\title{
Study of the Effect of Water Intake by the Matrix on the Optimization of the Fiber Matrix Interface Damage for a Composite Material by Genetic Algorithms
}

\author{
H. Temimi Lahouari, ${ }^{1}$ M. Allel, N. Belkaid, A. Boutaous, and R. Bouamrane \\ Mohamed Boudiaf University of Science and Technology of Oran, Oran, Algeria \\ ${ }^{1}$ husseintemimi@yahoo.fr
}

удК 539.4

\section{Исследование влияния поглощения воды смолой на оптимизацию повреждения поверхности раздела между волокном и матрицей в композитном материале с помощью генетических алгоритмов}

\author{
Х. Темими Лахоуари, М. Аллел, Н. Белкаид, А. Бутау, Р. Боуамране \\ Университет науки и техники им. Мухамеда Боудиафа, Оран, Алжир
}

Исследовано влияние набухания смоль (матрищы) вследствие поглощения воды на повреждение поверхности раздела между волокном и матрицей в композитном материале. Резульmаты, полученные с помощььо генетического алгоритма на основе вероятностной модели Вейбулла, показали хорошее соответствие между процессом моделирования и фактическим поведением двух материалов (Т300/914 и РЕЕК/АРС2). Более того, абсорбиия водь смолой (матрицей) значительно увеличивает повреждение поверхности раздела.

Ключевые слова: граница раздела, волокно, матрица, повреждение, набухание, вода, генетический алгоритм.

Introduction. According Aytac et al. [1] damage is the main cause of phenomena leading to failure by progressive loss of stiffness of material. It affects all final physical properties. The damage of material results into an irreversible change in the microstructure. This results in a variation of the elastic properties at the macroscopic level (relaxation of material, reduced Young's modulus). For Lemaitre and Chaboche [2], the theory describes the evolution of damage phenomena between the pristine and the initiation of macroscopic crack. The plastic ductile damage accompanies large plastic deformations, damage macrofragile can be caused by stress monotonous without significant permanent deformation.

For Ladevese [3, 4] the damage is the degradation more or less progressive material due to the emergence and development of microcracks and microvoids. The damage mechanics modelling of these phenomena depend of design of structures. For composite, there are not one, but several mechanisms of damage, and they are highly anisotropic. The idea is that the deterioration of a material can be described by its effects on elastic properties. Changes in elastic stiffness are 
indicators of the level of damage in the material. For the particular case of a unidirectional composite subjected to uniaxial tensile stress in the fiber direction, there is in general:

1. Rupture of fibers: boot from a default, if the fiber-matrix is low, it initiates a separation of the interface (interfacial failure). If the fiber breaks in an area where the matrix is already cracked, there may be transverse propagation of the crack.

2. Rupture of the matrix: initiation and propagation of a fault. When the crack reaches the fiber-matrix interface, there may be fiber breakage encountered, stress at the crack tip is important. At this meeting, there may be a change in direction of crack propagation in the matrix.

3. Degradation of the interface, which is the result of excess stress shear, tension or both. Decohesion of interface usually accompanies a broken fiber or crack propagation in the matrix.

Some matrices increase in volume when exposed to ambient humidity, under the effect of water absorption. This swelling, opposed, induces stress as would a thermal expansion. But in opposed thermal expansion, constraints (hydrostatic pressure when the swelling is isotropic) have an influence on the amount of water that can be absorbed [5-8]. The process of water absorption into the polymeric materials is described by Fig. 1. The first portion of the curve (from $t=0$ to $t=t_{1}$ ) is governed by the law of diffusion of water in the polymer to reach saturation for $t$ tending towards infinity or pseudo saturation $[9,10]$. Mass gain can then be stabilized as shown in Fig. 1, or increase after a latency, or continue to gradually increase depending on the material studied [11].

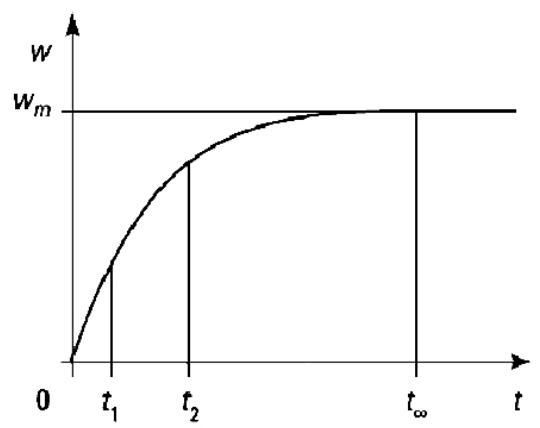

Fig. 1. Kinetics of diffusion of water into a polymeric material.

The diffusion of water depends on the amount of cavities and their size. During the diffusion, water molecules move from one site to the other with an activation energy (Fig. 2). Water is then considered as liquid water or free water [5, $6]$.

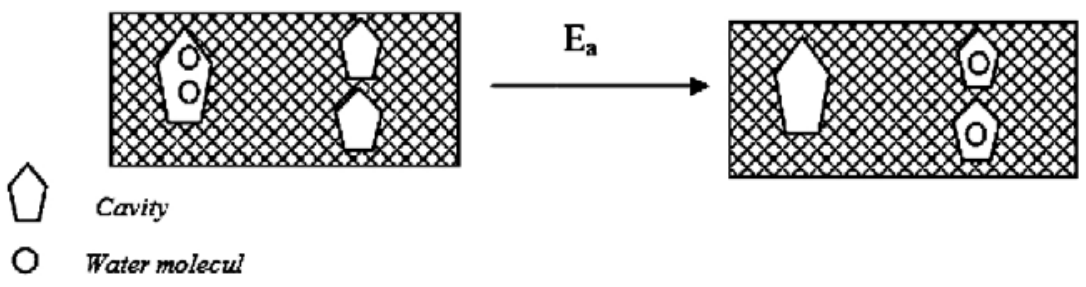

Fig. 2. Theories of free volumes. 
The high water absorption capacity of epoxy resins results from the presence on the epoxide chain of $\mathrm{OH}$ groups attracting polar water molecules. The diffusion of water is along the polar groups present on the polymer chains. The hydrophilic sites present in the material bind doubly (and sometimes triply) with the molecules or groups of molecules of water by means of hydrogen bonds. Diffusion is then performed by a trapping process. The water molecule linked to a site acquires sufficient energy $E_{a}$ to be freed and move to a new site [6] (Fig. 3).

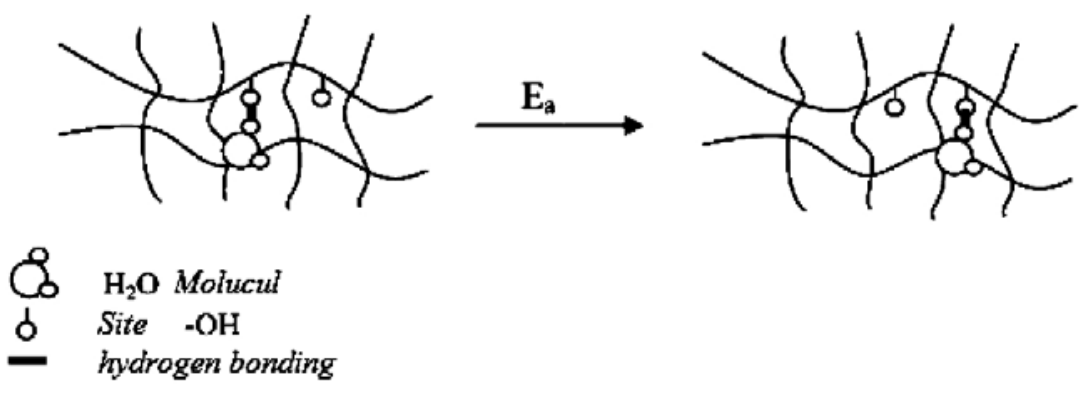

Fig. 3. Approach molecular.

Brun [5] shows that the water absorbed in the resin usually interacts with the polar groups by hydrogen bonds and that these interactions are completely reversible.

In this study, we will show the effect of water intake by the matrix on the damage of the interface fiber-matrix of a composite. We will use the Weibull model to determine the damage of the interface, Cox model to determine the objective function to optimize, and finally the laws relating to the linear diffusion of the water in the matrix.

\section{Review of Analytical Models.}

1.1. Absorption Model Diffusion. Diffusion models describe the first phase of water absorption in the material $\left(t=0\right.$ to $\left.t=t_{1}\right)$ in Fig. 1 . The kinetics of water diffusion in epoxy resins has been studied in many works [5, 6], all based on Fick's law in one dimension, that is diffusion is controlled by the concentration gradient of water between the environment and the material until saturation.

To simplify the analysis of diffusion, the following hypotheses have been considered:

(i) the diffusion coefficient $D$ is independent of the water concentration $C$;

(ii) the diffusion profile is linear in the $x$ direction.

We can write

$$
\frac{\partial C}{\partial t}=D \frac{\partial^{2} C}{\partial x^{2}},
$$

where $C$ is concentration and $D$ is diffusion coefficient.

Considering that the highest water concentration is at the surface and does not change during the absorption [6]. The absorption profile is continuous.

Monophase absorption model is described by Marque [6]. They developed equations to describe the behavior during conditioning. A first step corresponding to the diffusion phase involves the free water molecules and using Fick's second 
law in one dimension. It is shown by Brun [5] that in this model, the weight gain $M(\%)$ caused by the absorption can be expressed in terms of the diffusion coefficient $D$ and the increase in mass to saturation $M_{s}(\%)$ :

$$
M=M_{s} \frac{4}{h \sqrt{\pi}} \sqrt{D t},
$$

where $h$ is thickness of the sample (in $\mathrm{m}$ ) and $t$ is conditioning time. (This equation is valid when $D t / h^{2}<0.05$. This is for low conditioning time. After this phase of diffusion, the curve stabilizes.)

1.2. Model Based on the Micromechanical Approach. For a single fiber surrounded by matrix, many analytical solutions have been proposed by Cox [12], which provides the shape of the shear stress along the fiber length as the following form:

$$
\tau=\frac{E_{f} a \varepsilon}{2} \beta_{1} \operatorname{th}\left(\beta_{1} l / 2\right) .
$$

To simplify calculations, we take

$$
\beta_{1}^{2}=\frac{2 G_{m}}{E_{f} r_{f}^{2} \ln \left(R / r_{f}\right)},
$$

where $G_{m}$ is shear modulus of the matrix, $E_{f}$ is the Young modulus of the fiber, $\varepsilon$ is deformation, $a$ is radius of the fiber, $R$ is distance between fibers, and $\tau$ is shear stress of the interface.

These variables relating to the components of a composite material (fiber and matrix) are all taken into account through the formula (3). Therefore these variables will allow us to appreciate the result sets of genetic algorithm [13].

1.3. Model Based on the Statistical Approach. Damage to the matrix, when the stress is uniform, is given by formula (4) [14]:

$$
D_{m}=1-\exp \left\{-V_{m}\left[\frac{\sigma+\sigma_{m}^{T}}{\sigma_{0 m}}\right]^{m_{m}}\right\}
$$

where $\sigma$ is applied stress, $\sigma_{m}^{T}$ is heat stress, $V_{m}$ is the volume of the matrix, and $m_{m}$ and $\sigma_{0 m}$ are the Weibull parameters.

After the creation of a crack, a fragment of length $L$ will give rise to two fragments of size $L=L_{1}$ and $L_{2}=X L(1-X)$ ( $X$ being a random number between 0 and 1). At each crack of a fiber, a fiber-matrix debonding length $2 l$ will occur with a corollary decrease of creating a new crack in part because the matrix unloaded. At each increment of stress, the breaks are calculated. All blocks which break reaches 0.5 give rise to new cracks.

A broken fiber is discharged along its entire length. That is to say it can not break once. The rupture follows a law similar to that described for the matrix: 


$$
D_{f}=1-\exp \left\{-A_{f} L_{e q}\left[\frac{\sigma_{\max }^{f}}{\sigma_{0 f}}\right]^{m_{f}}\right\},
$$

where $\sigma_{\max }^{f}$ is the maximum stress applied and $L_{e q}$ is the length of the fibers would have the same break in a consistent manner.

2. Damage to the Interface (D).

Lemaitre and Chaboche consider a damaged solid in which an element of finite volume (Fig. 4) a notch large enough relative to heterogeneities is defined as follows [2]: $S$ is area representative volume element identified by its norm $n, S_{e}$ is effective resistance area (if $S_{e}<S$ ), and $S_{d}$ is damaged area, $S_{d}=S-S_{e}$.

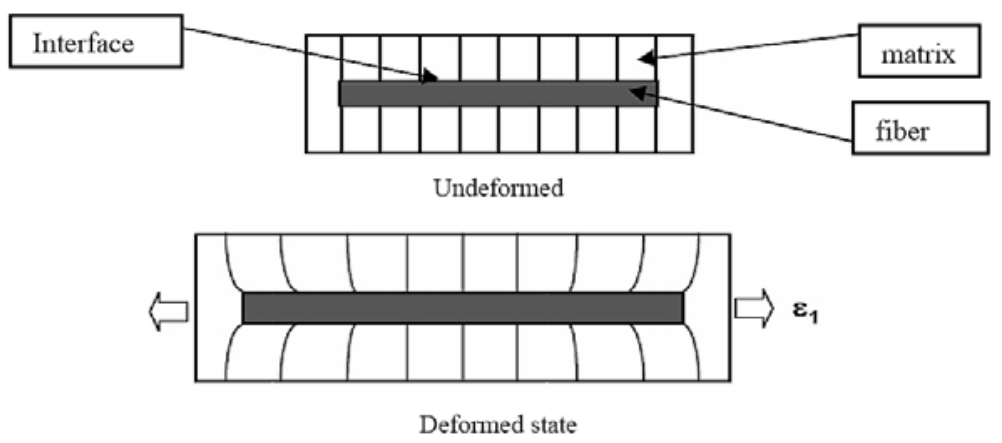

Fig. 4. Representative volume element.

The mechanical measurement of local damage in relation to $n$ is then characterized by $D=S_{d} / S$ : if $D=0$, the material is in a pristine or not damaged; if $D=1$, the volume element is broken into two parts along the plane normal $n$; if $0<D<1$, characterizes the state of damage defined, the macroscopic elastic behavior of the damaged material can be calculated using $D$ through the stiffness $[13,15$, 16].

\section{Numerical Simulation by a Genetic Algorithm (GA).}

3.1. Development. Our job is to study the influence of water absorption on the damage to the fiber matrix interface of a composite material. To do this, we chose to use a genetic optimization to evolve in the variation of moisture [Eqs. (1) and (2)]. This requires a set of mathematical and analytical tools defined by the Cox model, the theorem probabilistic Weibull model and linear laws of diffusion of water in a polymer. The principle begins by randomly generating an initial population and the selection of $D$ (diffusion coefficient), then change this population (the number 100 with a maximum of 50 equal to generation as stopping criterion) by a set of genetic operators (selection, crossover and mutation) and in each case calculating the diffusion coefficient of water in the matrix. The population is composed of chromosome genes represent the following variables: the mechanical stress which is between 80,100, and $120 \mathrm{~N}$, Young's module of the two materials, the shear modulus of the matrix, the fiber diameter, and distance $R$. The evaluation of each generation is made by an objective function derived from the Cox model, which includes all the variables defined at the beginning of the 
algorithm (mechanical properties of each component of the composite, the distance $R$ and the radius). To exploit the maximum tensile stresses and see the progress of our genetic algorithm, we chose a roulette selection and mutation selected value equal to 0.3 . Calculation by iteration values $C$ and $D$ were performed according to the principle of Fick's law, which has allowed the optimization of the results of our genetic model.

3.2. The Materials Used. Our choice to focus on composite materials T300/914 [thermosetting matrix composites (epoxy)] and PEEK/APC2 [thermoplastic composites-poly(ether ether ketone)], materials that we have used by Boutaous [13], and whose main characteristics of the carbon fiber are shown in Table 1. The index $f$ means that the parameter refers to a fiber.

T a b 1 e 1

Characteristics of the Carbon Fiber

\begin{tabular}{|l|c|c||}
\hline \multicolumn{1}{|c|}{ Properties of the carbon fiber } & Symbol [unit] & Value \\
\hline Density & $p_{f}, \mathrm{~kg} / \mathrm{m}^{3}$ & 1760 \\
\hline Diameter & $u, \mathrm{~m}$ & 10 \\
\hline Young's modulus & $E_{f}, \mathrm{GPa}$ & 231 \\
\hline Shear modulus & $G_{f}, \mathrm{GPa}$ & 92.1 \\
\hline Compression modulus & $K_{f}, \mathrm{GPa}$ & 123 \\
\hline Poisson's ratio & $v_{f}$ & 0.2 \\
\hline Coefficient of thermal expansion & $\alpha_{f},{ }^{\circ} \mathrm{C}^{-1}$ & $1.9 \cdot 10^{-5}$ \\
\hline
\end{tabular}

3.3. The Flowchart of Genetic Algorithm (shown in Fig. 5).

4. Simulation Results. A calculation was performed on two types of composite materials T300/914 and PEEK/APC2. We examined the variation of mechanical stress for different load values $(\sigma=80,100$, and $120 \mathrm{~N})$, and see the influence of the moisture by the water absorption on the damage to the interface. Figures 6-11 and 12-17, respectively, show each value of $\sigma$ and humidity for the level of damage to the interface of two materials: T300/914 and PEEK/APC2.

4.1. T300/914. Figures 6, 8, and 10 show that the damage " $D$ " interface starts at 0.3 for $\sigma=80 \mathrm{~N}$, then increases to a maximum value of 0.7 for $\sigma=120 \mathrm{~N}$, we note the presence of a symmetry of the damage to the interface.

Figures 7, 9, and 11 show that the damage " $D$ " interface starts at 0.3 for humidity $H=0$ and then increases to a maximum value of 0.9 for humidity $H>60 \%$.

4.2. PEEK/APC2. Figures 12, 14, and 16 show that the damage " $D$ " interface starts this time at 0.1 for $\sigma=80 \mathrm{~N}$, then increases to a maximum value of 0.5 for $\sigma=120 \mathrm{~N}$, we note the presence of a symmetry of the damage to the interface.

Figures 13, 15, and 17 show that the damage " $D$ " interface starts this time at 0.1 for humidity $H=0$, then increases to a maximum value of 0.7 for humidity $H>60 \%$.

We can say that the stress concentration along the length of the fiber and humidity create a strong degradation of the interface most important at the ends relative with the middle; values are lower compared to those found for the T300. 


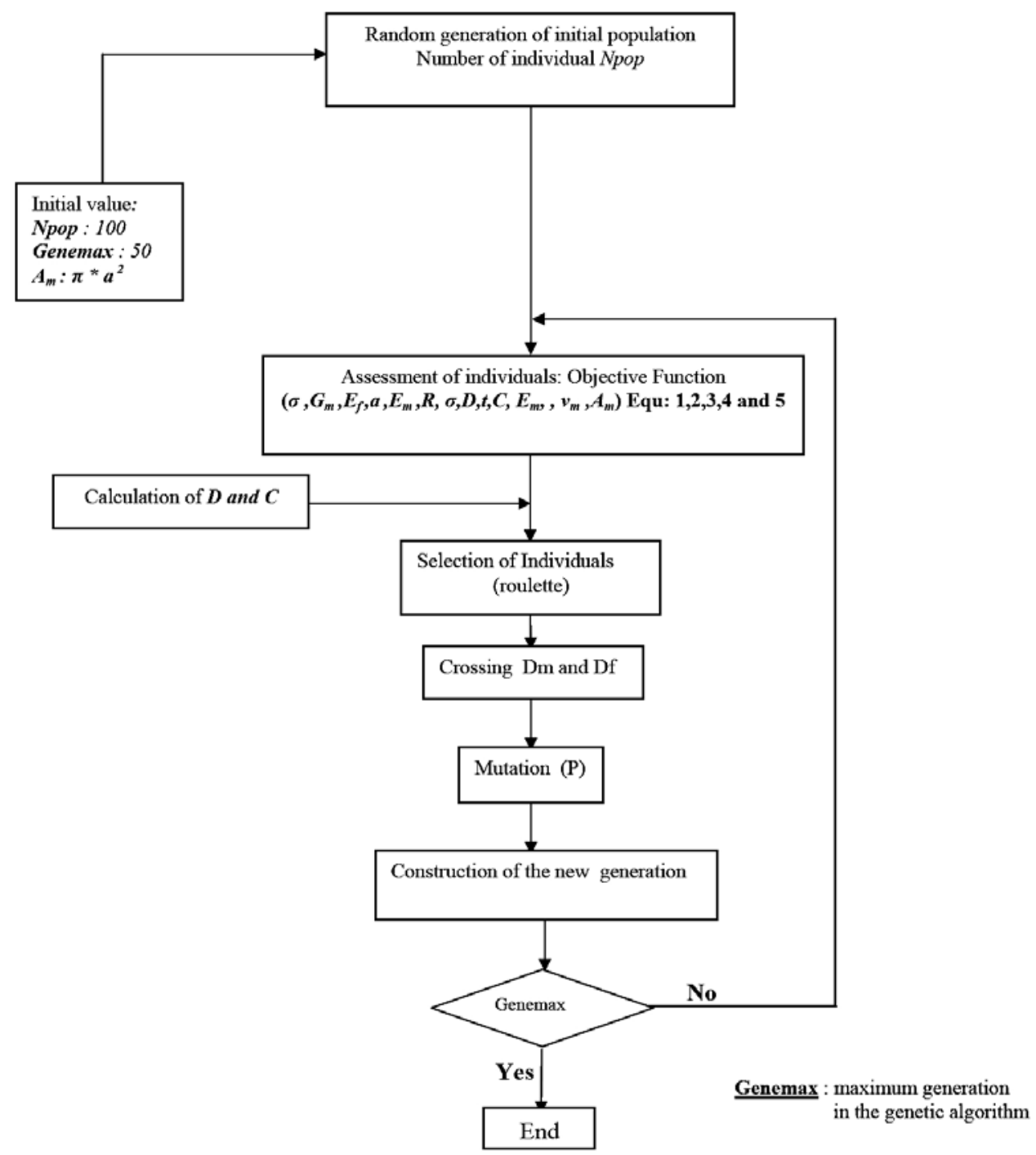

Fig. 5. The flowchart of genetic algorithm.

NB: We also observed that the humidity increases the damage level of 0.2 for both materials that have been the subject of study (T300: 0.7 to 0.9; PEEK: 0.5 to $0.7)$.

Conclusions. The results obtained by genetic algorithm calculation show that the level of damage is related to the mechanical stress applied for both materials that were studied the T300 and PEEK and indicate that the rate of absorption of water has a substantial influence on the gradual degradation of the interface.

Numerical simulation compared with the result obtained by genetic algorithm for T300 and PEEK show that the level of damage in a humid environment is more important to a dry environment. We can therefore say that the model properly took into account the phenomenon of damage to a unidirectional composite. It would be interesting to see the effect of thermal stress on the damage interface of fiber polymer matrix composite material. 


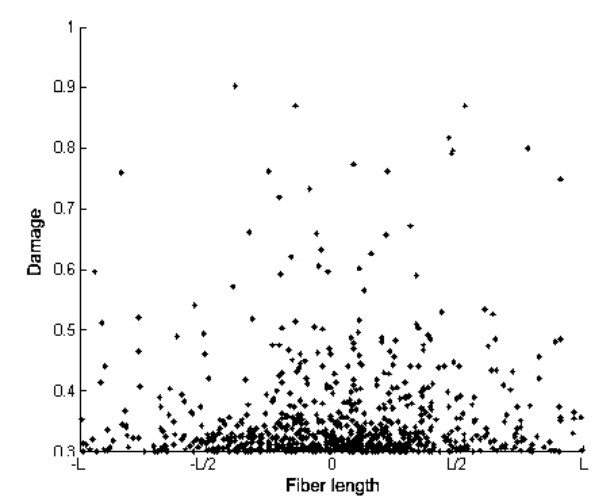

Fig. 6. Damage to the interface in a dry environment $(\sigma=80 \mathrm{~N})$.

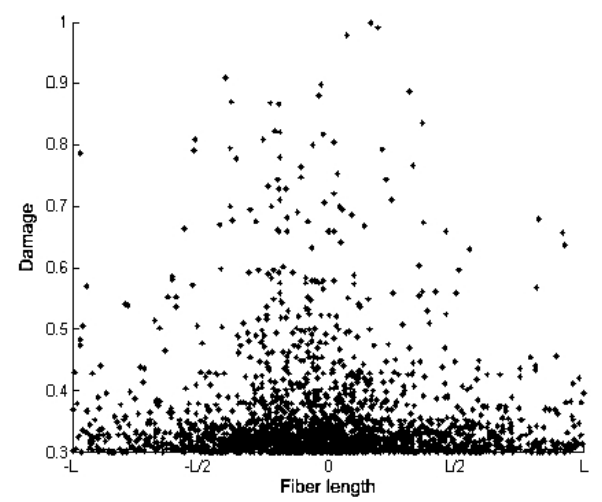

Fig. 8. Damage to the interface in a dry environment $(\sigma=100 \mathrm{~N})$.

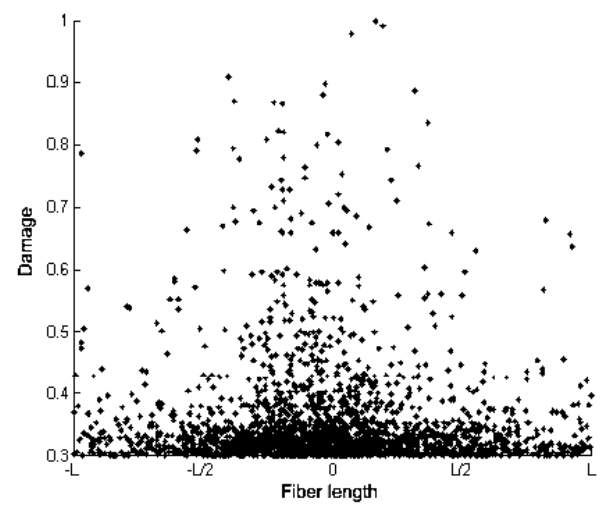

Fig. 10. Damage to the interface in a dry environment $(\sigma=120 \mathrm{~N})$.

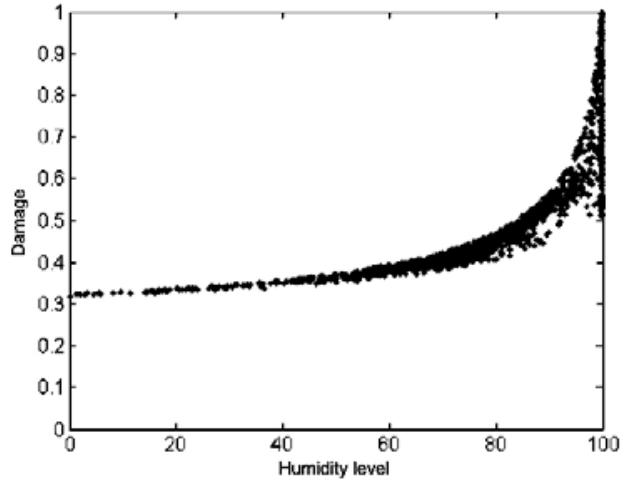

Fig. 7. Damage to the interface in a wet environment $(\sigma=80 \mathrm{~N})$.

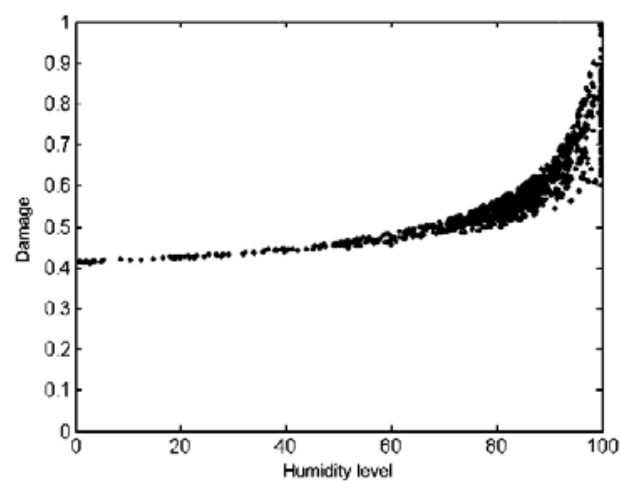

Fig. 9. Damage to the interface in a wet environment $(\sigma=100 \mathrm{~N})$.

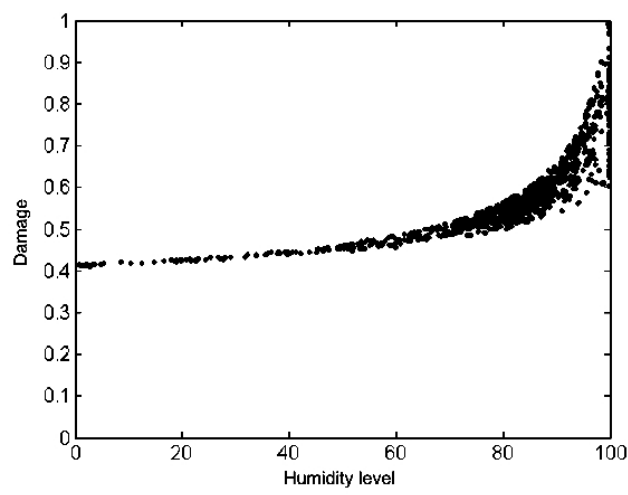

Fig. 11. Damage to the interface in a wet environment $(\sigma=120 \mathrm{~N})$.

\section{Резюме}

Досліджено вплив набухання смоли (матриці) внаслідок поглинання води на пошкодження поверхні поділу між волокном і матрицею в композитному матеріалі. Результати, що отримані за допомогою генетичного алгоритму на 


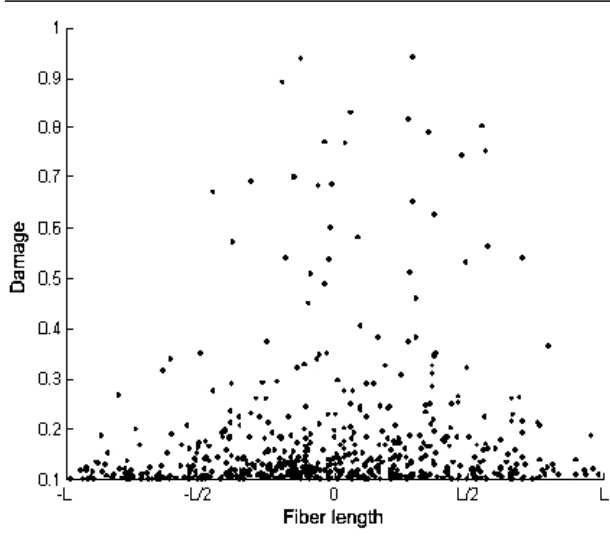

Fig. 12. Damage to the interface in a dry environment $(\sigma=80 \mathrm{~N})$.

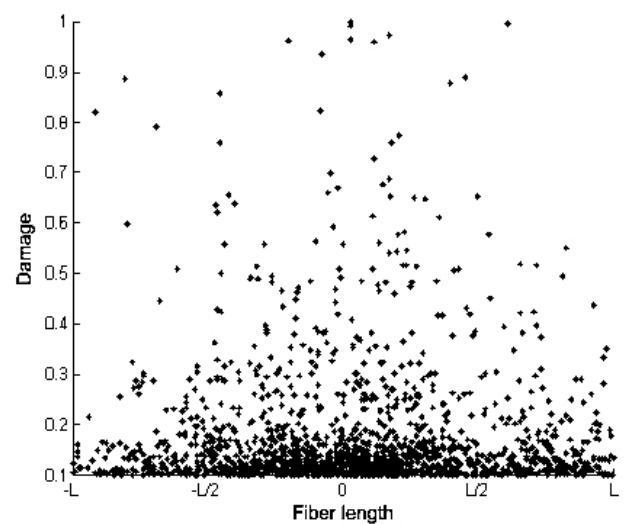

Fig. 14. Damage to the interface in a dry environment $(\sigma=100 \mathrm{~N})$.

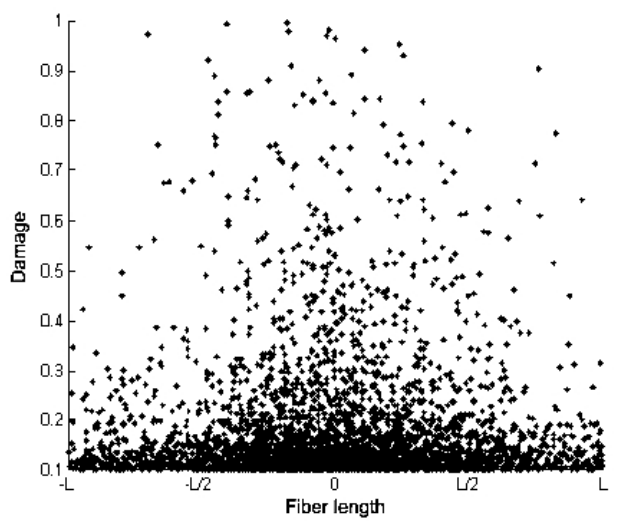

Fig. 16. Damage to the interface in a dry environment $(\sigma=120 \mathrm{~N})$.

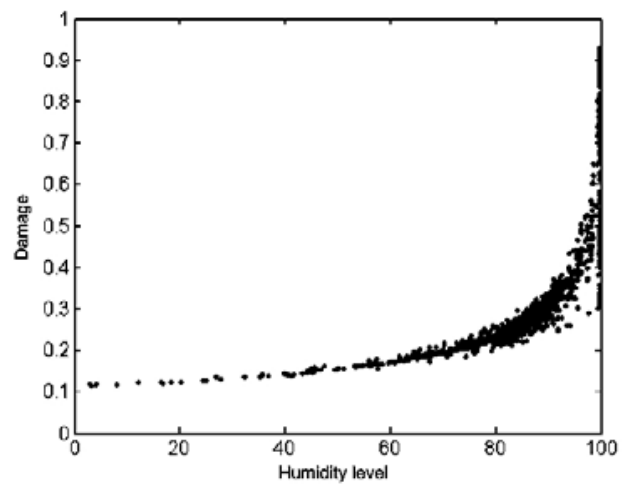

Fig. 13. Damage to the interface in a wet environment $(\sigma=80 \mathrm{~N})$.

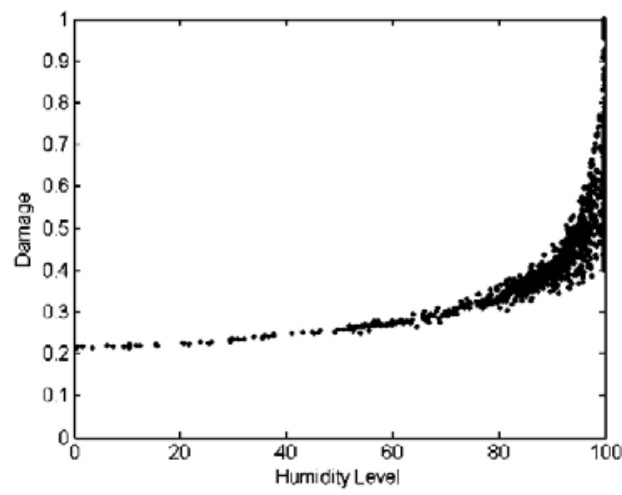

Fig. 15. Damage to the interface in a wet environment $(\sigma=100 \mathrm{~N})$.

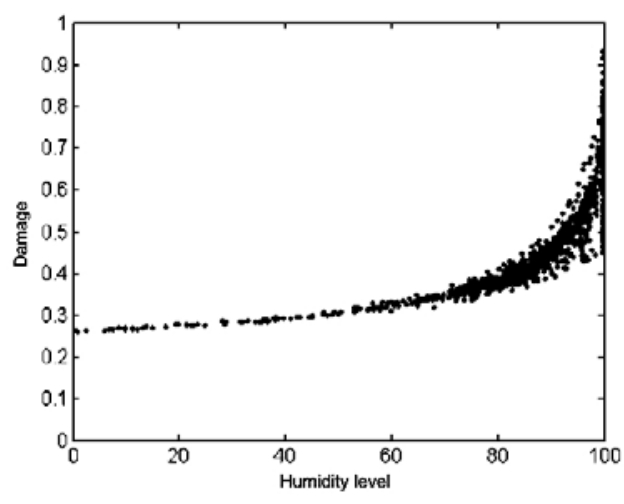

Fig. 17. Damage to the interface in a wet environment $(\sigma=120 \mathrm{~N})$.

основі імовірнісної моделі Вейбулла, показали хорошу відповідність між процесом моделювання і фактичною поведінкою двох матеріалів (Т300/914 i PEEK/APC2). Більш того, абсорбція води смолою (матрицею) значно збільшує пошкодженість поверхні поділу. 
1. H. Aytac, J. Renard, and G. Verchery, "Mesure de l'endommagement dans les materiaux composites a matrice resine par absorption hydroscopique differentielle," in: JNC 3 (Sept. 21-23, 1982, Paris), pp. 141-149.

2. J. Lemaitre and J. L. Chaboche, Mechanics of Solid Materials, Cambridge University Press (1994).

3. P. Ladevese and G. Lubineau, "Pont entre micro et meso mecaniques des composites stratifies," Compos. Rendus Mecan., 331, 537-544 (2003).

4. P. Ladevese and G. Lubineau, "On a damage mesomodel for laminates: micromechanics basis and improvement," Mech. Mater., 35, 763-775 (2003).

5. E. Brun, Vieillissement Hygrothermique d'un Composite Resine Epoxyde Silice et Impact sur sa Rigidite Dielectrique, These a l'Universite Joseph Fourier Grenoble I (2009).

6. G. Marque, Absorption de l'Eau par les Polymeres, These a l'Universite de Savoie (2009).

7. D. Bourega Ramoun, M. Djillali, L. Temimi, and A. Boutaous, "Contribution to the modeling of the thermoelastic behavior of composite materials," Int. Rev. Phys., 6, No. 3, 254-260 (2012).

8. L. Temimi, D. Ramoun, N. Belkaid, and A. Boudghene Stambouli, "Study of the water intake by a damaged matrix composite subjected to a uniaxial compression," Int. Rev. Phys., 2, No. 2, 49-55 (2012).

9. J. Gassan, "A study of fibre and interface parameters affecting the fatigue behaviour of natural fibre composites," Composites: Part A, 33, 369-374 (2002).

10. R. Kahraman and M. Al-Harthi, "Moisture diffusion into aluminum powder filled epoxy adhesive in sodium chloride solutions," Int. J. Adhes. Adhesiv., 25, No. 4, 337-341 (2005).

11. K. Derrien and P. Gilormini, "The effect of applied stresses on the equilibrium moisture content in polymer," Sripta Mater., 56, No. 4, 297-299 (2007).

12. H. L. Cox, "The elasticity and strength of paper and other fibrous materials," Brit. J. Appl. Phys., 12, 72-79 (1952).

13. A. Boutaous, B. Peseux, L. Gornet, and A. Belaidi, "A new modeling of plasticity coupled with the damage and identification for carbon fibre composites laminates," Compos. Struct., 74, 1-9 (2006).

14. W. Weibull, "A statistical theory of the strength of materials," Royal Swed. Acad. Eng. Sci. Proc., 151, 1-45 (1939).

15. A. Boutaous, M. Elchikh, M. Abdelouahab, and A. Belaidi, "A computational strategy for the localization and fracture of laminated composites. Part 1. Development of a localization criterion adapted to model damage evolution time-delay," Strength Mater., 43, No. 5, 519-525 (2011).

16. A. Boutaous, M. Elchikh, M. Abdelouahab, and A. Belaidi, "A computational strategy for the localization and fracture of laminated composites. Part 2. Life prediction by mesoscale modeling for composite structures," Strength Mater., 43, No. 6, 645-653 (2011). 